\title{
ВИПАДОК УНІЛАТЕРАЛЬНОГО ШИЛОПІД'ЯЗИКОВОГО СИНДРОМУ, ПОЄДНАНОГО З ГІПОПЛАЗІЄЮ ВЕРТЕБРАЛЬНОЇ АРТЕРІї
}

\author{
ФВ. М. Мацькевич ${ }^{1}$, Т. Л. Ленчук' ${ }^{1}$ І. В. Жулкевич ${ }^{2}$, Ю. О. Мицик ${ }^{3}$ \\ 'ДВНЗ "Івано-Франківський національний медичний університет" \\ ${ }^{2}$ Тернопільський національний медичний університет імені І. Я. Горбачевського МОз України \\ ${ }^{3}$ Львівський національний медичний університет імені Данила Галицького
}

РЕзЮМЕ. Випадок асоціації одностороннього лівобічного шилопід'язикового синдрому (ШПС) з гіпоплазією хребтової артерії $\epsilon$ рідкісною патологією, тому його представлення та обговорення $\epsilon$ актуальними.

Мета - описання випадку виявлення поєднаної рідкісної патології шилоподібного відростка та вертебральної артерії за допомогою променевих методів.

Матеріал і методи. Обстежено 1 пацієнта, 2000 р.н., що звернувся до сімейного лікаря зі скаргами на підвищення артеріального тиску до 180/100 мм рт. ст., яке триває останні 2 роки та яке він не пов'язує з певними причинами. Додатково турбує біль у лівій половині шиї. Травм, втрати свідомості та оперативних втручань не було. У плановому порядку призначене ультразвукове дослідження гілок аорти, рентгенографію шийного відділу хребта, МДКТ-ангіографію судин голови та шиї.

Результати. При функціональних пробах встановлено помірні гемодинамічно значущі порушення кровотоку по вертебральній артерії зліва за рахунок компресії в поперечному каналі, видовжену кісткову структуру з чітко диференційованими кірковою та губчастою речовинами.

Висновки. Клінічно підозрювані випадки ШПС можуть бути виявлені за допомогою звичайних рентгенограм, але для уточнення діагнозу необхідна КТ. Комп'ютерна томографія повинна бути виконана згідно із стандартним протоколом з постпроцесинговою обробкою отриманих зрізів. Обов'язковим у таких випадках $є$ дослідження гілок аорти для виключення супутньої судинної патології.

КлючовІ СлОВА: шилопід'язиковий синдром; гіпоплазія хребтової артерії; комп'ютерна томографія; рентгенографія; ультразвукова діагностика.

Вступ. Шилопід'язиковий синдром (ШПС, англ. - Eagle syndrome) - рідкісний патологічний симптомокомплекс $(0,16 \%$ клінічних проявів з $4 \%$ виявлених аномалій шилопід'язикового комплексу в популяції), який виникає внаслідок подовження шилоподібного відростка, чи його надмірного вигину та кальцинації шилопід'язикової зв'язки (ШП3), чи, за даними окремих авторів, - лише елонгації шилоподібного відростка (ШВ), і мають характер неврологічних чи судинних проявів [1-3]. Гіпоплазія хребетної артерії (ГХА) теж $\epsilon$ рідкісною патологією (10\% від популяції), що частіше локалізується справа [4]. Випадок асоціації одностороннього лівобічного ШПС з ГХА $є$ доволі рідкісним, тому потребує представлення та обговорення.

Опис випадку (case report). Пацієнт віком 19 років звернувся до сімейного лікаря зі скаргами на підвищення артеріального тиску до 180/100 мм рт. ст., яке триває останні 2 роки та яке він не може пов'язати з певними причинами. Чоловік нормостенічної статури, без шкідливих звичок, у сімейному анамнезі гіпертензія виявлена тільки у бабусі по материнській лінії як компонент метаболічного синдрому. 3 відомостей амбулаторної карти пацієнта - перенесені вітряна віспа та краснуха у дитинстві. Травм, втрати свідомості та хірургічних втручань не було. Додатково паці$\epsilon н т$ зазначає, що тільки на лівому боці, після сну на лівій стороні або при вимушеному тривалому положенні з повернутою вліво головою з'являється біль у лівій половині шиї, який минає через 5-6 годин. Мазі з нестероїдними протизапальними препаратами викликають помірне покращення. 3 приводу вищевказаних скарг раніше не обстежувався. При детальному опитуванні вказує на часті відчуття стороннього тіла та першіння в горлі, які $\epsilon$ короткотривалими та не створюють особливого дискомфорту. При щорічному медичному огляді патології з боку ЛОР-органів та очного дна не виявлено.

Пацієнта скеровано на стаціонарне лікування, де йому в плановому порядку призначене ультразвукове дослідження гілок аорти, під час якого виявлені помірно гемодинамічно значущі порушення кровотоку по вертебральній артерії зліва за рахунок компресії в поперечному каналі, виявленої при функціональних пробах. Сегмент V1: систолічна швидкість - $72 \mathrm{~cm} / \mathrm{c}$, діастолічна $30 \mathrm{~cm} / \mathrm{c}, \mathrm{RI}-0,58$. Сегмент V2: систолічна швидкість - $48 \mathrm{~cm} / \mathrm{c}$, діастолічна - $20 \mathrm{~cm} / \mathrm{c}, \mathrm{RI}-0,51$. За призначенням невролога проведено рентгенографію шийного відділу хребта в двох проекціях для виключення у ньому дегенеративно-дистрофічних змін як етіології цервікалгії (рис. 1). На рентгенограмі шийного відділу хребта в проекції шилопід'язикової зв'язки виявлена видовжена 


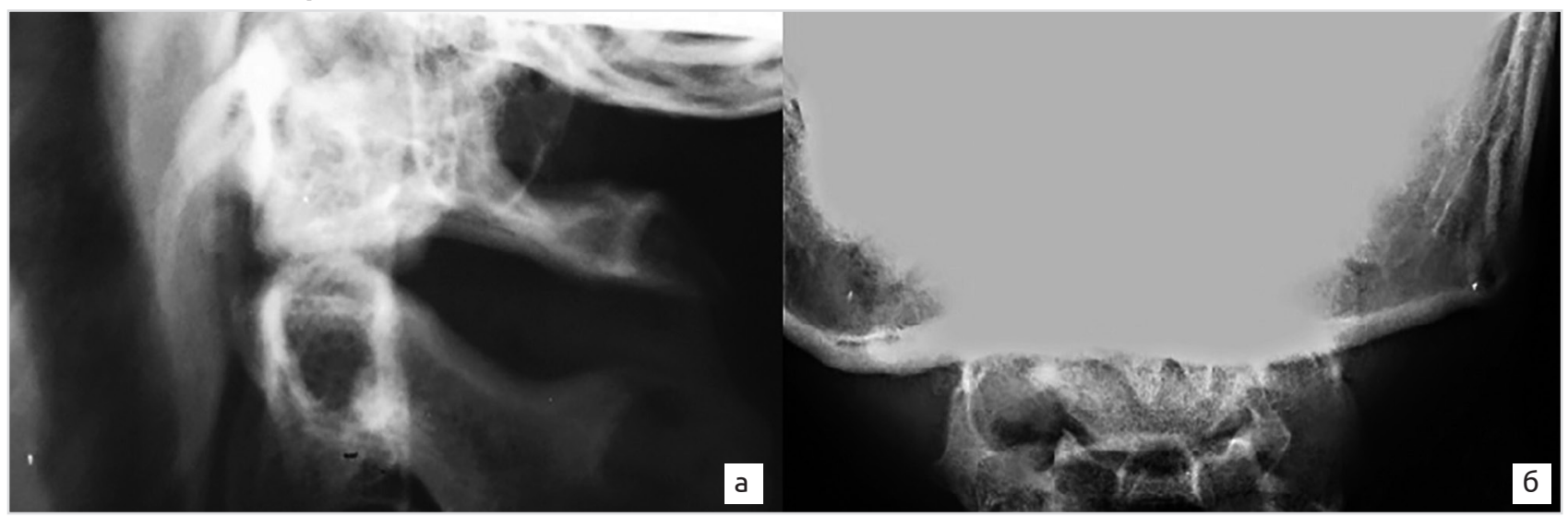

Рис. 1. Фрагмент (прицільний) рентгенограми шийного відділу хребта: а) у боковій проекції з візуалізацією подовженого шилоподібного відростка; 6) у прямій проекції тінь з відносно чітким по периферії кірковим контуром на тлі гілки нижньої щелепи.

кісткова структура з чітко диференційованими кірковою та губчастою речовинами, яка у прямій проекції визначається зліва як додаткова тінь на тлі нижньої щелепи.

Лікуючий лікар скерував пацієнта на 160-зрізову мультидетекторну комп'ютерно-томографічну ангіографію (МДКТ-а) голови та шиї для деталізації змін. Виявлено, що вертебральні артерії візуалізуються на всьому протязі, ліва нерівномірно звужена на всій протяжності до 2,8 мм, права протяжністю до 5,3 мм (рис. 2). 3ліва шилоподібний відросток завдовжки до 3,5 см, справа - до 2 см (рис. 3). МДКТ-а ознаки гіпоплазії лівої вертебральної артерії. ШПС зліва.

Результати й обговорення. Власне подовження шилоподібного відростка (уні- чи білатеральне) без клінічних проявів не вважається ШПС [5]. Також немає чітких вказівок, яку довжину ШВ вважати нормою, а яку видовженням. Watt W. Eagle, американський оториноларинголог, який першим описав ШПС та прізвище якого дало епонімічну назву цього синдрому, вважав еталонним діапазоном норми довжину ШВ 2,5-3 см [6]. Однією 3

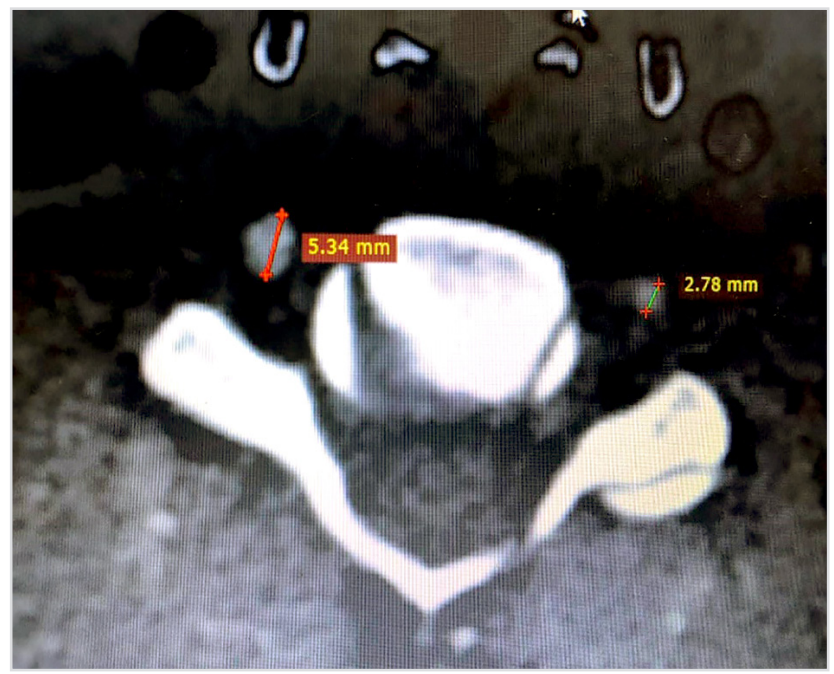

Рис. 2. МДКТ-ангіограма обох вертебральних артерій в аксіальній проекції.

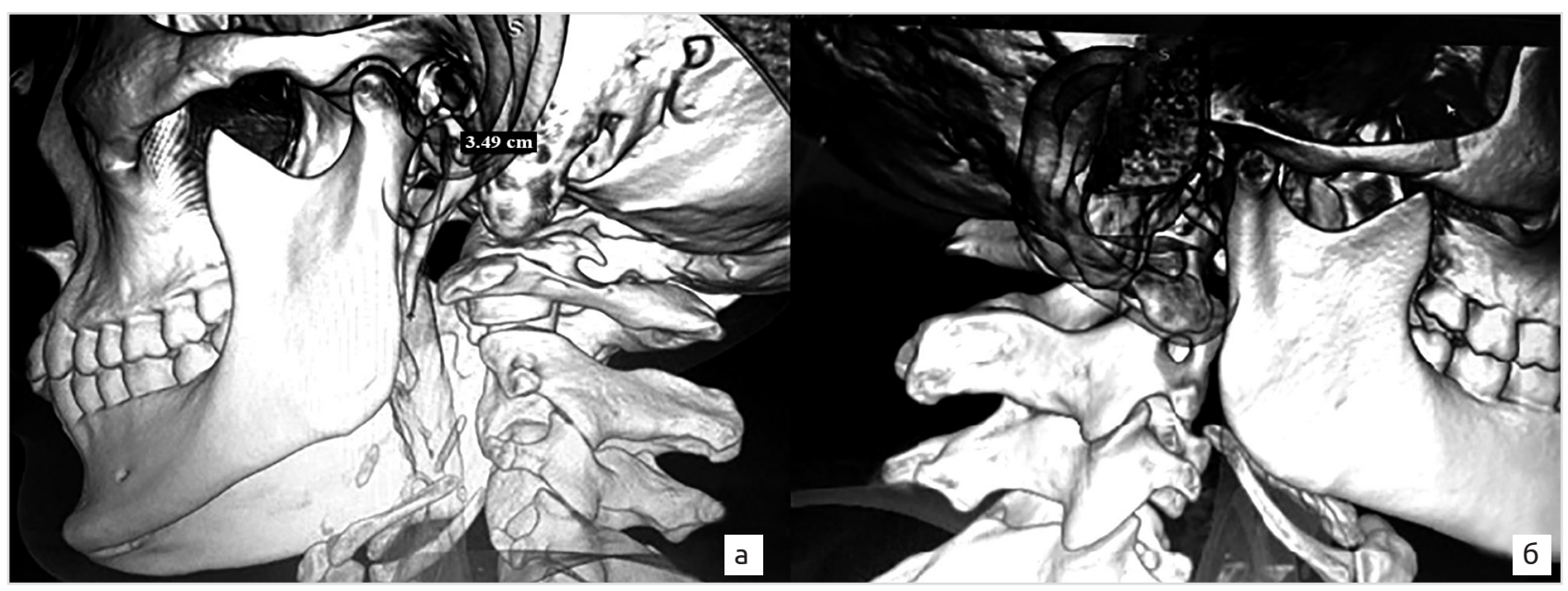

Рис. 3. Тривимірне реконструктивне зображення постпроцесингового етапу МДКТ з обраним показовим заміром: а) лівого видовженого шилоподібного відростка (3,49 см); 6) правого шилоподібного відростка. 
Огляди літератури, оригінальні дослідження, погляд на проблему, випадок з практики, короткі повідомлення найбільших довжин ШВ, які спричиняли патологічні зміни, була 5,5 мм, а однією з найдовших мінералізованих ШПЗ - 6,0 см [7, 8].

Існують теорії вродженого (внаслідок персистенції хрящового попередника) та набутого (через травму або ідіопатичну мінералізацію зв'язки) шПС [9]. Також описано та підтверджено випадки спадкового білатерального ШПС у трьох поколіннях однієї сім'ї [10].

Поширеність гіпоплазії хребтової артерії (ГХА) складає від 1,9 \% до 26,5 \%. Фактично це може бути пов'язано з відсутністю стандартного її визначення. Зазвичай ГХА вважали нешкідливим анатомічним варіантом. Але в останні роки з'являються докази того, що ГХА може бути фактором ризику вертебробазилярного інсульту [11]. Виявлені дані свідчать про те, що гіпоплазія хребетних артерій може сприяти виникненню ішемічних проявів у задньому сегменті кровообігу, особливо за наявності інших факторів ризику. Незважаючи на труднощі та суперечності в точному визначенні та оцінці поширеності гіпоплазії хребетної артерії, ультразвукові дослідження показують, що зменшений приплив крові, який спостерігається іпсилатерально до гіпопластичної хребетної артерії, може спричинити локальну мозкову гіпоперфу-

\section{ЛITЕРАТУРА}

1. Eagle's syndrome: a case report of a unilateral elongated styloid process / S. A. Warrier, N. Kc, S. K., D. M. Harini // Cureus. - 2019. - Vol. 11 (4). - P. e4430. DOI: 10.7759/ cureus.4430.

2. Eagle W. W. Elongated styloid processes: report of two cases / W. W. Eagle // Arch Otolaryngol. - 1937. Vol. 25. - P. 584-587.

3. Camarda A. J. Stylohyoid chain ossification: a discussion of etiology / A. J. Camarda, C. Deschamps, D. I. Forest // Oral Surg. Oral Med. Oral Pathol. -1989. - Vol.67.-P. 508-514.

4. Atlas fracture with concomitant vertebral artery hypoplasia, a rare but potentially hazardous combination: A case report / G. Vynichakis, T. B. Grivas, H. Moschouris [et al.] // Cureus. - 2019. - Vol. 11 (3). - P. e4172.

5. Mupparapu M. The mineralized and elongated styloid process: a review of current diagnostic criteria and evaluation strategies / M. Mupparapu, M. D. Robinson // Gen. Dent. - 2005. - Vol. 53 (1). - P. 54-59.

6. Eagle W. W. Elongated styloid process: symptoms and treatment / W. W. Eagle // Arch. Otolaryngol. - 1958. Vol. 64. - P. 172-176.

7. Bahgat M. Eagle's syndrome, a rare cause of neck pain / M. Bahgat, Y. Bahgat, A. Bahgat // BMJ Case Reports. - 2012. - P. bcr2012006278.

зію та подальшу вогнищеву неврологічну симптоматику [12].

Клінічно синдром класифіковано на два типи. Перший $є$ клінічним ШПС та трапляється в осіб, які мали в анамнезі тонзилектомію та біль. Цей біль проявляється як невралгія в глотці та дисфагія і, ймовірно, є результатом організації фіброзної рубцевої тканини навколо V, VII, IX та X черепних нервів. Друга група пацієнтів, що не мають тонзилектомії в анамнезі, скаржаться на біль у шиї та голові. Цей стан пов' язаний із пошкодженням внутрішньої чи зовнішньої сонної артерії (або іï гілок) латерально або медіально відхиленим ШВ. Клінічно випадки з підозрою на ШПС слід вивчати безпосередньо за допомогою КТ, без звичайних рентгенограм, щоб скоротити час до діагностики. КТ повинна бути переважно субміліметрична, із осьовими, коронарними та сагітальними реконструкційними зображеннями та реконструкцією об'ємного відтворення [13].

Висновки. Рентгенологічне досліження при шилопід'язиковому синдромі та ангіосонографія при гіпоплазії вертебральної артерії $є$ первинними методами, які за потреби мають доповнюватись детальнішою діагностикою для вивчення повноти причин клінічної картини.
8. Eagle's syndrome: a case report / C. S. Moon, B. S. Lee, Y. D. Kwon [et al.] // Journal of the Korean Association of Oral and Maxillofacial Surgeons. - 2014. - Vol. 40 (1). P. 43-47.

9. Murtagh R. D. CT findings associated with Eagle syndrome / R. D. Murtagh J. T. Caracciolo, G. Fernandez // AJNR Am. J. Neuroradiol. - 2001. - Vol. 22. - P. 1401-1402.

10. Morrison R. J. Aetiology of Eagle syndrome: ossification of the stylohyoid ligament / R. J. Morrison, P. J. Morrison // QJM: An International Journal of Medicine. - 2019. Vol. 112, Issue 6. - P. 467.

11. Vertebral artery hypoplasia: a predisposing factor for posterior circulation stroke? / F. Perren, D. Poglia, T. Landis, R. Sztajzel // Neurology. - 2007. - Vol. 68. - P. 65-67.

12. Is vertebral artery hypoplasia a predisposing factor for posterior circulation cerebral ischemic events? / A. H. Katsanos, M. Kosmidou, A. P. Kyritsis, S. Giannopoulos // A Comprehensive Review. Eur. Neurol. - 2013. Vol. 70. - P. 78-83.

13. Eagle's syndrome: a case report and CT pictorial review / S. Giovanni, C. C. Daniele, V. R. Maria, C. C. Maria // Radiol. Case Rep. - 2019. - Vol. 14 (2). - P. 141-145. 
Огляди літератури, оригінальні дослідження, погляд на проблему, випадок з практики, короткі повідомлення REFERENCES

1. Warrier, S.A., Kc, N., K, S., \& Harini, D.M. (2019). Eagle's syndrome: A Case report of a unilateral elongated styloid process. Cureus, 11 (4), e4430. doi:10.7759/cureus.4430.

2. Eagle, W.W. (1937). Elongated styloid processes: report of two cases. Arch. Otolaryngol., 25, 584-587. Retrieved from: http://dx.doi.org/10.1001/archotol.1937. 00650010656008

3. Camarda, A.J., Deschamps, C., \& Forest, D.I. (1989). Stylohyoid chain ossification: a discussion of etiology. Oral Surg. Oral Med. Oral Pathol., 67, 508-514. Retrieved from: https://www.ncbi.nlm.nih.gov/pubmed/2497419.

4. Vynichakis, G., Grivas, T.B., Moschouris, H., Filippou, D., \& Skandalakis, P. (2019). Atlas Fracture with Concomitant Vertebral Artery Hypoplasia, a Rare but Potentially Hazardous Combination: A Case Report. Cureus, 11 (3), e4172. doi:10.7759/cureus.4172.

5. Mupparapu, M., \& Robinson, M.D. (2005). The mineralized and elongated styloid process: a review of current diagnostic criteria and evaluation strategies. Gen. Dent., 53 (1), 54-59.

6. Eagle, W.W. (1958). Elongated styloid process: symptoms and treatment. Arch. Otolaryngol., 64, 172-176.

7. Bahgat, M., Bahgat, Y., \& Bahgat, A. (2012). Eagle's syndrome, a rare cause of neck pain. BMJ Case Reports, bcr2012006278. doi:10.1136/bcr-2012-006278.
8. Moon, C.S., Lee, B.S., Kwon, Y.D., Choi, B.J., Lee, J.W., \& Lee, H.W. (2014). Eagle's syndrome: a case report. Journal of the Korean Association of Oral and Maxillofacial Surgeons, 40 (1), 43-47. doi:10.5125/jkaoms.2014.40.1.43.

9. Murtagh, R.D., Caracciolo, J.T., \& Fernandez, G. (2001). CT findings associated with Eagle syndrome. AJNR Am. J. Neuroradiol., 22, 1401-1402.

10. Morrison, R.J., \& Morrison. P.J. (2019). Aetiology of Eagle syndrome: ossification of the stylohyoid ligament. QJM: An International Journal of Medicine, 112, 6, 467. https://doi.org/10.1093/qjmed/hcy168.

11. Perren, F., Poglia, D., Landis, T., \& Sztajzel, R. (2007). Vertebral artery hypoplasia: a predisposing factor for posterior circulation stroke? Neurology, 68, 65-67.

12. Katsanos, A.H., Kosmidou, M., Kyritsis, A.P., \& Giannopoulos, S. (2013). Is vertebral artery hypoplasia a predisposing factor for posterior circulation cerebral ischemic events? Eur. Neurol., 70, 78-83. Retrieved from: https:// doi.org/10.1159/000351786

13. Giovanni, S., Daniele, C.C., Maria, V.R., \& Maria, C.C. (2019). Eagle's syndrome: a case report and CT pictorial review. Radiol. Case Rep.,14 (2), 141-145.

\title{
СЛУЧАЙ УНИЛАТЕРАЛЬНОГО ШИЛОПОДЪЯЗЫЧНОГО СИНДРОМА В СОЧЕТАНИИ С ГИПОПЛАЗИЕЙ ВЕРТЕБРАЛЬНОЙ АРТЕРИИ
}

\author{
๑В. М. Мацькевич ${ }^{1}$, т. Л. Ленчук ${ }^{1}$, И. В. Жулкевич ${ }^{2}$, Ю. А. Мицик ${ }^{3}$,

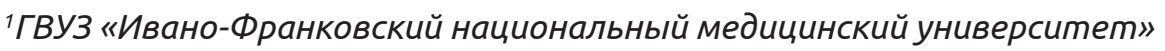 \\ ${ }^{2}$ Тернопольский национальный медицинский университет имени И. Я. Горбачевського Мз Украины \\ З Львовский национальный медицинский университет имени Данила Галицкого
}

РЕЗЮМЕ. Случай ассоциации одностороннего левостороннего шилоподъязычного синдрома (ШПС) с гипоплазией позвоночной артерии является редкой патологией, поэтому его представление и обсуждение является актуальным.

Цель - описание случая выявления сочетанной редкой патологии шиловидного отростка и вертебральной артерии с помощью лучевых методов.

Материал и методы. Обследован 1 пациент, 2000 года рождения, который обратился к семейному врачу с жалобами на повышение артериального давления до 180/100 мм рт. ст., которое он отмечает последние 2 года и не связывает с определенными причинами. Дополнительно беспокоит боль в левой половине шеи. Травм, потери сознания и оперативных вмешательств не было. В плановом порядке назначено ультразвуковое исследование ветвей аорты, рентгенографию шейного отдела позвоночника, МДКТ-ангиографию сосудов головы и шеи.

Результаты. При функциональных пробах установлены умеренные гемодинамически значимые нарушения кровотока по вертебральной артерии слева за счет компрессии в поперечном канале, удлиненная костная структура с четко дифференцированными корковым и губчатым веществами.

Выводы. Клинически подозрительные случаи ШПС могут быть обнаружены с помощью обычных рентгенограмм, но для уточнения диагноза необходима КТ. Компьютерная томография должна быть выполнена в соответствии со стандартным протоколом с постпроцесинговой обработкой полученных срезов. Обязательным в таких случаях является исследование ветвей аорты для исключения сопутствующей сосудистой патологии.

КЛЮЧЕВЫЕ СЛОВА: шилоподъязычный синдром; гипоплазия позвоночной артерии; компьютерная томография; рентгенография; ультразвуковая диагностика. 
Огляди літератури, оригінальні дослідження, погляд на проблему, випадок з практики, короткі повідомлення

THE CASE OF UNILATERAL STYLOID SYNDROME IN COMBINATION WITH VERTEBRAL ARTERY HYPOPLASIA

\author{
@V. M. Matskevych'1, T. L. Lenchuk', I. V. Zhulkevych², Yu. O. Mytsyk ${ }^{3}$ \\ 1 Ivano-Frankivsk National Medical University \\ 2. Horbachevsky Ternopil National Medical University \\ ${ }^{3}$ Danylo Halytskyi Lviv National Medical University
}

SUMMARY. The case of association of unilateral left-sided styloid syndrome with vertebral artery hypoplasia is a rare pathology and therefore requires its presentation and discussion.

The aim - to identify the combined rare pathology of styloid syndrome and vertebral artery suture, using radiation techniques.

Material and Methods. One patient, born in 2000, was examined, sought medical care with complaints of an increase in blood pressure up to $180 / 100 \mathrm{~mm} \mathrm{Hg}$. This condition last for 2 years and he didn't associate with certain reasons. The pain in the left half of the neck was present. There were no injuries, unconsciousness and surgery. The ultrasound examination of the aortic branches, radiography of the cervical spine, and MDCT-angiography of the vessels of the head and neck were assigned.

Results and Discussion. Moderate hemodynamically significant disorders of the blood flow along the left vertebral artery due to compression in the transverse canal at functional tests, an elongated bone structure with clearly differentiated cortical and spongy substance were established.

Conclusions. Clinically suspected cases of styloid syndrome can be detected using conventional radiographs, but a CT scan is needed to clarify the diagnosis. Computed tomography should be performed according to standard protocol with a postprocessing of the obtained slices. In such cases, it is mandatory to study the branches of the aorta to eliminate concomitant vascular pathology.

KEY WORDS: styloid syndrome; vertebral artery hypoplasia; computed tomography; radiography; ultrasound diagnostics.

Отримано 25.10 .2019 